\title{
Hubungan Pengendapan Suspended Sedimen Dengan Kerapatan Mangrove Pada Perairan Romokalisari, Surabaya
}

\author{
Muhammad Yusuf Arifin*, Nirwani Soenardjo, Chrisna Adi Suryono \\ Departemen IImu Kelautan, Fakultas Perikanan dan IImu Kelautan, Universitas Diponegoro \\ Jl. Prof.H.Soedarto S.H, Tembalang,Semarang, Jawa Tengah 50275 Indonesia \\ e-mail : arifinyusuf10@gmail.com
}

\begin{abstract}
ABSTRAK: Romokalisari merupakan bagian hilir dari sungai Lamong, dimana daerah tersebut merupakan daerah pasang surut dan rawan terhadap banjir. Romokalisari banyak ditumbuhi oleh mangrove yang sangat rapat. Tujuan penelitian ini adalah untuk mengetahui pengaruh kerapatan mangrove terhadap laju pengendapan suspended sedimen pada perairan Romokalisari, Surabaya. Sampel sedimen diambil dari 8 stasiun yang terbagi dalam wilayah muara, mangrove dan laut, dimana masing-masing stasiun diulang 4 kali dengan periode setiap minggu. Analisis sampel sedimen menggunakan metode hydrometer dan analisis data menggunakan One Way Anova. Hasil penelitian menunjukkan bahwa ada perbedaan laju pengendapan suspended sedimen antara muara, mangrove dan laut, dengan nilai $p=0,046<0,05$. Laju pengendapan suspended tertinggi terdapat pada stasiun 1 di wilayah muara dengan nilai sebesar $86,97 \mathrm{~g} / \mathrm{cm}^{2} / \mathrm{minggu}$ dan laju pengendapan suspended terendah terdapat pada stasiun 2 di wilayah mangrove dengan nilai sebesar14,36g $/ \mathrm{cm}^{2} / \mathrm{minggu}$.
\end{abstract}

Kata kunci: Kerapatan, Laju Pengendapan, Sediment trap, Hydrometer, Romokalisari

\section{Relation of Suspended Sediment Rate With Mangrove Density in Romokalisari Waters, Surabaya}

ABSTRACT: Romokalisari is downstream part of the Lamong River, where the area is tidal and prone to flooding. Romokalisari is overgrown by very dense mangroves. The aim of this study was to determine the effect of mangrove density on suspended sediment rate in Romokalisari, Surabaya. Sediment sample were taken from 8 statios divided into estuaries, mangroves, and sea areas, each station was repeated 4 times with periods each week. Analysis of sediment samples using a hydrometer and data analysis using One Way Anova. The results showed that there were differences in suspended sedimentation rates between estuaries, mangroves and seas, with a value of $p=0,046<0,05$. The highest suspended deposition rate is at station 1 in the estuary area with a value of $86.97 \mathrm{~g} / \mathrm{cm}^{2} /$ week and the lowest suspended deposition rate is at station 2 in the mangrove area with a value of $14.36 \mathrm{~g} / \mathrm{cm}^{2} /$ week.

Keywords: Density, Sedimentary Deposition Rate, Hydrometer, Romokalisari

\section{PENDAHULUAN}

Perairan Romokalisari merupakan bagian hilir dari sungai Lamong yang merupakan daerah rawan banjir diakibatkan oleh meluapnya air sungai. Romokalisari juga merupakan daerah pasang surut (tidal flat) dan terdapat ekosistem mangrove tumbuh subur.

Hoque et al. (2015), membuktikan bahwa mangrove dapat menangkap sedimen untuk mencegah adanya abrasi maupun erosi. Prawira dan Pamungkas (2014), menyatakan keberadaan kawasan mangrove mampu menghasilkan sedimentasi lumpur, dimana pengendapan lumpur yang dihasilkan mangrove tersebut merupakan tanggul alami dalam mencegah banjir rob. Petra et al. (2012), juga menyatakan bahwa semakin tinggi kerapatan mangrove maka semakin rendah laju sedimen transpor dan begitupun sebaliknya. Aysha et al. (2015), menyatakan laju sedimentasi tertinggi terdapat pada mangrove yang rapat yaitu $\left(97,02 \mathrm{mg} / \mathrm{cm}^{2} / \mathrm{hari}\right)$. Laju sedimentasi terendah pada mangrove yang paling jarang yaitu $\left(5,91 \mathrm{mg} / \mathrm{cm}^{2} /\right.$ hari) Rerata tingkat sedimentasi adalah 
$39,82 \mathrm{mg} / \mathrm{cm}^{2} /$ hari, tingkat sedimentasi tersebut tergolong tinggi. Schwarzer et al. (2016), menunjukkan pada musim hujan laju sedimentasi mencapai sekitar $0,2 \mathrm{~cm} /$ hari sedangkan pada musim kemarau laju sedimentasinya hanya $0,15 \mathrm{~cm} /$ hari. Hasil tersebut menunjukkan pada musim penghujan terjadi peningkatan dinamika sedimen dan akumulasi yang lebih tinggi di hutan mangrove. Aritonang et al. (2016), menyatakan laju pengendapan sedimen untuk stasiun 1 adalah $2,645 \times 10^{-11} \mathrm{~m}^{3} / \mathrm{s}$, untuk stasiun 2 adalah $1,421 \times 10^{-10} \mathrm{~m}^{3} / \mathrm{s}$ dan stasiun 3 adalah $1,625 \times 10^{-9} \mathrm{~m}^{3} / \mathrm{s}$. Laju pengendapan pada stasiun 3 terlihat jauh lebih tinggi dibandingkan dengan stasiun 2 dan stasiun 1, dan indikasi penyebabnya adalah stasiun 3 berada pada ujung pulau Anakan bagian selatan yang berhadapan langsung dengan sungai Banyuasin dan sungai Lalan yang membawa sejumlah endapan-endapan dari daratan sehingga menyebabkan tingginya laju pengendapan pada stasiun tersebut. Satriadi (2012), Menyatakan pola sebaran konsentrasi sedimen sebanding dengan kecepatan arus, semakin besar arus maka konsentrasi sedimen juga akan semakin besar. Syahrial (2018), menyatakan Kondisi hutan mangrove di Utara Indonesia berdasarkan indikator kualitas lahan dan ekologi komunitas terlihat masih tergolong baik atau bagus. Walaupun tingkat keanekaragaman dan dominansinya tergolong rendah, sedangkan keseragaman atau kemerataan vegetasinya tergolong labil. Penelitian ini dilakukan untuk mengetahui apakah kerapatan mangrove pada perairan Romokalisari mempengaruhi laju pengendapan suspended sedimen.

\section{MATERI DAN METODE}

Materi yang digunakan dalam penelitian ini adalah Sedimen dan Mangrove. Data yang diambil antara lain adalah laju sedimentasi, sampel sedimen untuk analisis ukuran butir dan analisis vegetasi mangrove untuk mengetahui kerapatan mangrove. Data pendukung yang digunakan dalam penelitian ini meliputi data insitu (Suhu, $\mathrm{pH}$ dan salitas perairan) dan data exsitu (Arus dan pasang surut yang bersumber dari BMKG Maritim Perak Surabaya).

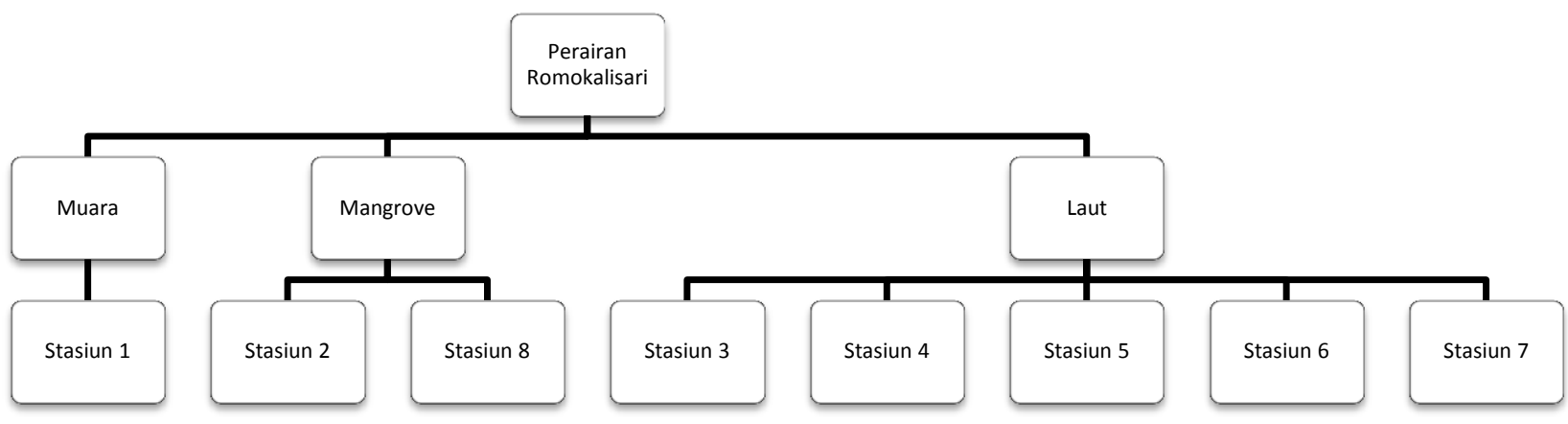

Gambar 1. Penentuan Stasiun Penelitian

Pengambilan sampel sedimen dengan sediment trap (gambar 2) dilakukan pada perairan Romokalisari yang terbagi menjadi 3 lokasi yaitu muara, mangrove dan laut, dimana pada lokasi muara ada 1 stasiun sediment trap, Lokasi mangrove ada 2 stasiun sediment trap dan lokasi laut ada 5 stasiun sediment trap, untuk lebih jelasnya dapat dilihat pada Gambar 1. Pengambilan sampel sedimen dilakukan dengan menggunakan sediment trap yang diletakkan di dasar perairan sesuai dengan titik lokasi yang telah ditentukan. Sediment trap ditinggal selama 7 hari, setelah itu sampel sedimen yang berada di dalam sediment trap diambil, kemudian dianalisis jenis tekstur dan ditimbang untuk mengetahui laju sedimentasinya di laboratorium. Pengambilan sampel dilakukan sebanyak 4 kali setiap 7 hari sekali. Sampel sedimen dihitung dengan rumus sebagai berikut :

$$
\mathrm{L}=\frac{\mathrm{BS}}{\text { Jumlah hari } \times \mathrm{t} \times \mathrm{k} \times \mathrm{r}^{2}}
$$

Keterangan : $\mathrm{L}=$ Laju Sedimentasi ( $\mathrm{g} /$ liter/minggu); BS = Berat kering sedimen $(\mathrm{g}) ; \mathrm{t}=$ Tinggi sediment trap $(\mathrm{cm}) ; \mathrm{k}=$ Konstanta $(3.14) ; \mathrm{r}$ : Jari-jari lingkaran sediment trap $(\mathrm{cm})$

Analisis vegetasi mangrove dengan metode transek (transect methods) dilakukan pada stasiun 2 dan stasiun 8 . Transek diletakkan tegak lurus garis pantai menuju daratan dengan 
ukuran $10 \times 10$ m panjangnya, tergantung kondisi lapangan. Perhitungan kerapatan mangrove menggunakan rumus seperti berikut (Hayati et al., 2017) :

$$
\mathrm{Di}=\frac{\mathrm{Ni}}{\mathrm{A}}
$$

Keterangan $: \mathrm{Di}=$ Kerapatan jenis; $\mathrm{Ni}=$ Jumlah total tegakan dari jenis mangrove; $A$ : Luas total area plot/ Transek

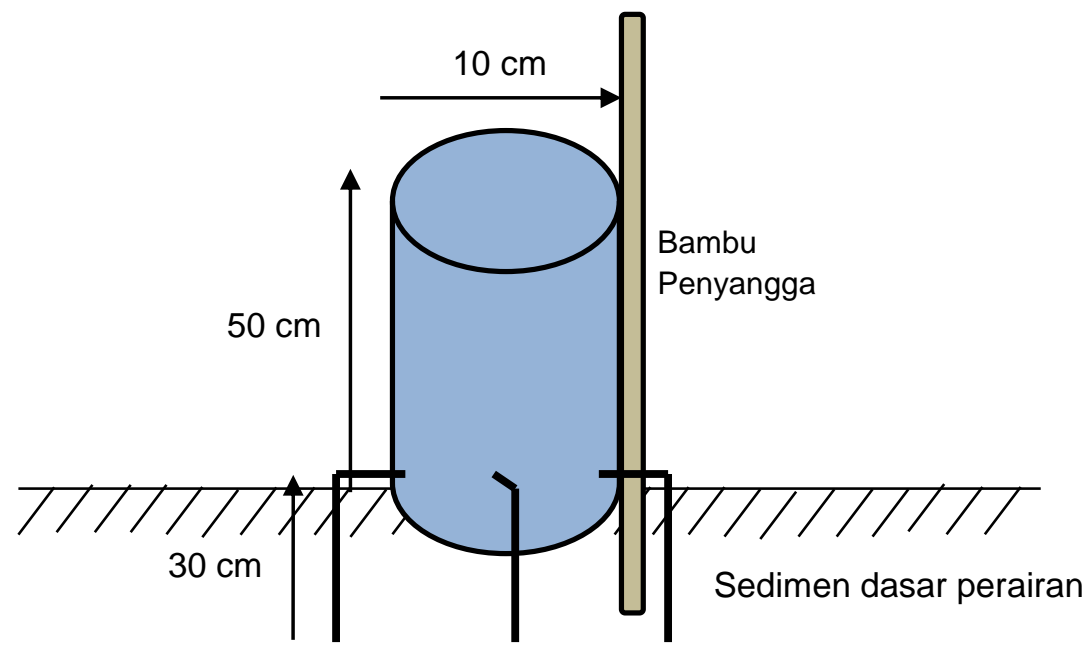

Gambar 2. Sediment Trap Modifikasi

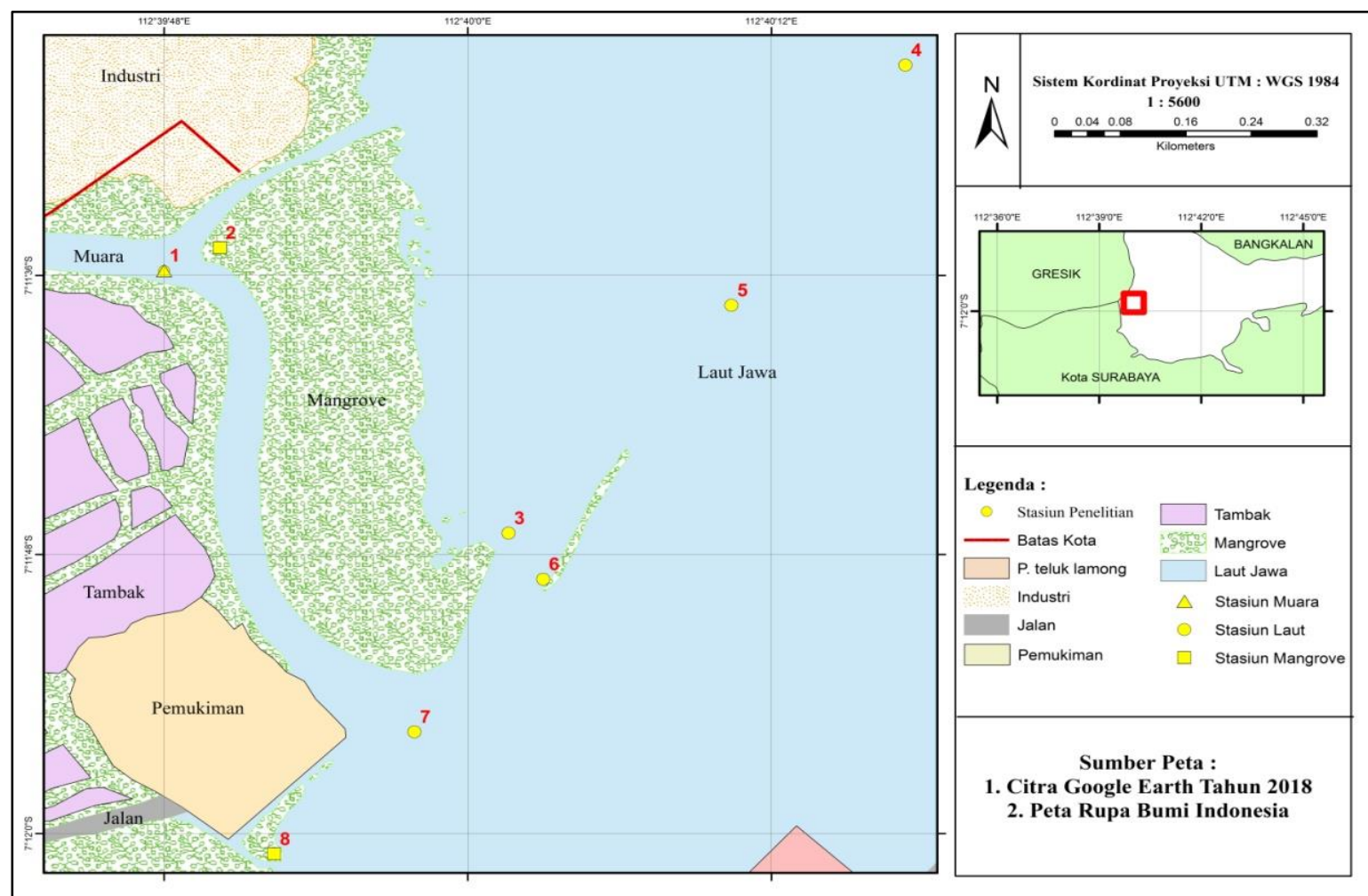

Gambar 3. Peta Lokasi Penelitian Pengaruh Kerapatan Mangrove Terhadap Laju Pengendapan Suspended Sedimen pada Perairan Romokalisari, Surabaya 


\section{HASIL DAN PEMBAHASAN}

Laju pengendapan suspended sedimen dari 8 stasiun sangat bervariasi, begitu juga dengan kerapatan mangrove memiliki hasil yang berbeda. Hasil tersebut dapat dilihat pada Tabel 1. Laju pengendapan suspended sedimen pada stasiun 1 sebesar $86,97 \mathrm{~g} / \mathrm{cm}^{2} / \mathrm{ming} g \mathrm{u}$, stasiun 2 sebesar $14,36 \mathrm{~g} / \mathrm{cm}^{2} / \mathrm{minggu}$, stasiun 3 sebesar $37,99 \mathrm{~g} / \mathrm{cm}^{2} / \mathrm{minggu}$, stasiun 4 sebesar 43,65 $\mathrm{g} / \mathrm{cm}^{2} /$ minggu, stasiun 5 sebesar $53,89 \mathrm{~g} / \mathrm{cm}^{2} /$ minggu, stasiun 6 sebesar $36,02 \mathrm{~g} / \mathrm{cm}^{2} / \mathrm{minggu}$, stasiun 7 sebesar $28,21 \mathrm{~g} / \mathrm{cm}^{2} /$ minggu dan stasiun 8 sebesar $19,12 \mathrm{~g} / \mathrm{cm}^{2} / \mathrm{minggu}$. Laju pengendapan terbesar ada di stasiun 1 yang berlokasi di muara dan laju pengendapan terendah ada di stasiun 2 yang berlokasi di kawasan mangrove. Stasiun 1 memiliki nilai tertinggi karena berada di muara sungai, dimana laju sedimentasi dipengaruhi oleh aliran air dari arah darat maupun dari arah laut yang kemudian bertemu di muara sungai. Pernyataan tersebut diperkuat oleh Aritonang et al. (2016), bahwa stasiun yang berada di muara perairan pulau anakan memiliki laju sedimentasi tertinggi. Petra et al. (2012), juga memperkuat pernyataan bahwa tingginya tingkat sedimentasi pada lokasi penelitian di pantai Karangsong Indramayu diakibatkan dari rendahnya tingkat kerapatan hutan mangrove, dikarenakan lokasi penelitian merupakan perairan terbuka (windward) dimana berhadapan langsung dengan gelombang datang. Stasiun 2 memiliki nilai terendah karena berada pada kawasan mangrove dan kemungkinan tidak selalu tergenang oleh air, hanya saat pasang tertinggi saja wilayah tersebut tergenang. Banyak sedikitnya air laut yang masuk ke ekosistem mangrove mempengaruhi jumlah sedimen yang terbawa dan terperangkap pada stasiun 2. Grafik laju sedimentasi pada perairan Romokalisari dapat dilihat pada Gambar 4.

Perakaran mangrove yang ditemukan pada 2 stasiun pengamatan yaitu $A$. marina dan $A$. alba berakar Pneumatophore sedangkan $R$. mucronata dan $R$. apiculata berakar tunjang. Akarakar mangrove berfungsi sebagai perangkap (trapped) partikel tanah dan mengendapkannya, sehingga menyebabkan endapan lumpur tidak hanyut oleh arus dan gelombang akibat adanya peningkatan gesekan dan penurunan kecepatan arus pasang dan surut yang masuk ke kawasan mangrove. Perakaran mangrove baik akar Pneumatophore dan akar tunjang akan membuat tanah/sedimen yang berada di ekosisitem mangrove lebih stabil karena cengkraman dari akar-akar tersebut. Paputungan et al. (2017), menyatakan ekosistem mangrove yang didominasi jenis Rhizophora sp yang memiliki sistem perakaran yang kompleks dapat menyebabkan perlambatan arus dan menyebabkan kondisi tenang pada saat pasang dan akan memerangkap sedimen.

Nilai kerapatan rata-rata dari kategori pohon, sapling dan seddling pada stasiun 1 sebesar 68,992 ind/ha dan pada stasiun 2 sebesar 9,822 ind/ha. Kerapatan pada stasiun 1 dan 2 didominasi oleh spesies aviecenia dimana hal tersebut dikarenakan letak kedua stasiun berada di zona yang bersentuhan dengan laut dan zona tersebut sangat cocok untuk pertumbuhan mangrove spesies tersebut. Petra et al. (2012), memperkuat pernyataan bahwa pada pantai Karangsong Indramayu jenis avicennia mendominasi dilokasi yang terkena pasang surut. Jenis

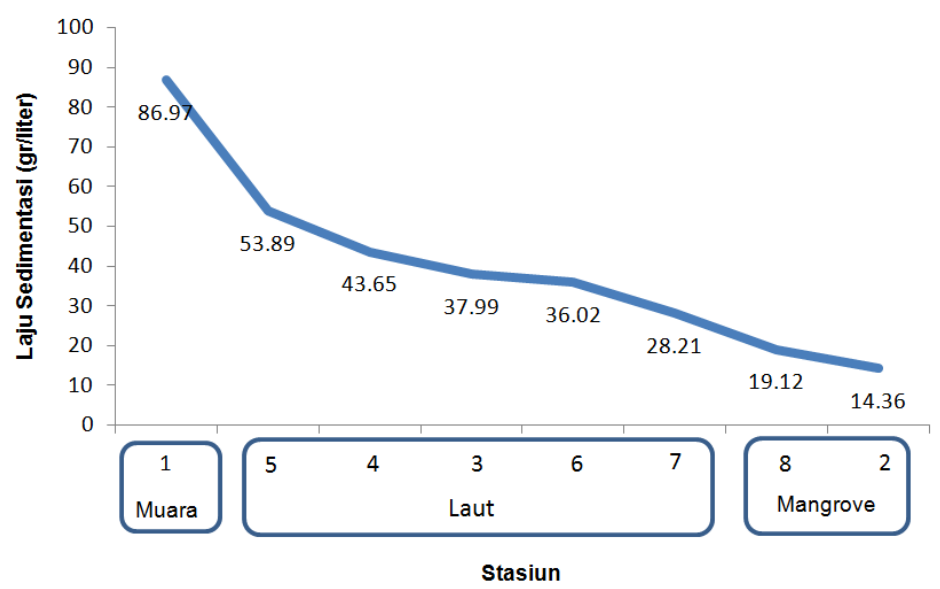

Gambar 2. Grafik Laju Sedimentasi pada perairan Romokalisari 
Tabel 1. Hasil Laju Pengendapan Suspended Sedimen dan Kerapatan Mangrove pada Perairan Romokalisari

\begin{tabular}{cccc}
\hline Stasiun & Lokasi & Laju Sedimentasi $(\mathrm{gr} / \mathrm{cm} / \mathrm{ming} g \mathrm{u})$ & Kerapatan Mangrove (ind/ha) \\
\hline 1 & Muara & 86,97 & \\
2 & Mangrove & 14,36 & 68,922 \\
8 & & 19,12 & 9,822 \\
3 & & 37,99 & \\
4 & & 43,65 & \\
5 & Laut & 53,89 & \\
6 & & 36,02 & \\
7 & & 28,21 & \\
\hline
\end{tabular}

substrat yang ditemui dilapangan juga sangat cocok untuk tempat tumbuh berkembangnya mangrove yaitu berjenis lumpur, seperti yang diungkapkan oleh Setiawan (2013), bahwa daerah dengan tingkat ketebalan mangrove yang tinggi cenderung mempunyai substrat dengan tekstur lempung liat berdebu. Data yang diperoleh dari kerapatan di lokasi pengamatan yang masuk pada kategori baik adalah stasiun 1 dimana nilai kerapatan mangrove $>1500$ ind/ha menurut Kepmen LH No.201 tahun 2004. Stasiun 2 memiliki kategori kurang baik karena nilai kerapatannya $<1500$ ind/ha, hal tersebut dikarenakan mangrove pada lokasi tersebut masih baru tumbuh berbanding terbalik dengan stasiun 1 yang sudah terlihat lebih lama tumbuhnya.

Arus sangat berperan terhadap penyebaran sedimen dan abrasi pantai. Arus dilokasi penelitian menunjukkan banyak pembelokan karena adanya bangunan pantai seperti adanya pelabuhan teluk lamong. Vegetasi mangrove juga berperan dalam pembelokan arah arus pada perairan Romokalisari. Pembelokan arah arus akan mengurangi kecepatan arus dan mempengaruhi terjadinya pengadukan sedimen (Upwelling) lalu menyebabkan proses pengendapan suspended sedimen menjadi terpusat hanya disekitar perairan Romokalisari tersebut. Aritonang et al. (2016), menyatakan bahwa kecepatan arus pada pulau anakan sangat rendah sehingga tingkat sedimentasi tinggi. Petra et al. (2012), juga menyatakan bahwa kecepatan arus berbanding terbalik dengan laju sedimentasi, semakin besar kecepatan arus maka semakin kecil laju sedimentasi dan begitupun sebaliknya.

Pasang surut pada perairan Romokalisari memperoleh nilai formzahl sebesar 0,98 dimana nilai tersebut termasuk dalam $0,25<\mathrm{F} \geq 1,5$ yang merupakan pasang surut campuran condong ke harian ganda (Mixed Tide Prevailing Semidiurnal). Jenis pasang surut ini diperkuat dengan pernyataan Satriadi (2012), bahwa jenis pasang surut pada perairan Paciran Lamongan yang letaknya dekat dengan perairan Romokalisari juga berjenis campuran condong ke harian ganda Pasang surut dapat membangkitkan arus pasang yang dapat mengangkut sedimen dari tengah laut menuju ke sekitar perairan romokalisari, begitupula sebaliknya. Pasang surut mempengaruhi banyak sedikitnya air laut yang menuju ke arah darat. Semakin banyak air laut yang menuju ke darat maka sedimen suspended yang dibawa dan diendapakan pada perairan semakin banyak, didukung dengan pernyataan Widjojo (2010), bahwa transportasi sedimen di muara sungai di sebabkan oleh arus pasang surut gelombang dan arus sungai air tawar.

Berdasarkan hasil pengolahan pada SPSS diperoleh nilai signifikansi sebesar 0,004. Berdasarkan nilai tersebut dapat diketahui bahwa $0,004<0,05$, Hal tersebut menunjukkan nilai signifikasnsi lebih kecil daripada 0,05 maka berarti signifikan. Hasil analisis One Way Anova diatas mengartikan bahwa ada hubungan yang signifikan antara kerapatan mangrove dengan laju pengendapan suspended sedimen pada perairan Romokalisari, Surabaya.

\section{KESIMPULAN}

Berdasarkan hasil penelitian yang dilakukan, kerapatan mangrove pada stasiun 1 sebesar $68,922 \mathrm{ind} / \mathrm{ha}$ dan stasiun 2 sebesar $9,822 \mathrm{ind} / \mathrm{ha}$. Laju pengendapan suspended sedimen yang tertinggi pada stasiun 1 sebesar $86,97 \mathrm{~g} / \mathrm{cm}^{2} / \mathrm{minggu}$ dan yang terendah pada stasiun 2 sebesar $14.36 \mathrm{~g} / \mathrm{cm}^{2} /$ minggu. Kerapatan mangrove dan laju pengendapan suspended sedimen memiliki hubungan yang signifikan. . 


\section{UCAPAN TERIMAKASIH}

Artikel ini merupakan bagian dari skripsi yang berjudul "Pengaruh Kerapatan Mangrove Terhadap Laju Pengendapan Suspended Sedimen pada Perairan Romokalisari, Surabaya". untuk memperoleh gelar Sarjana Strata Satu Program Studi IImu Kelautan, Fakultas Perikanan dan IImu Kelautan Universitas Diponegoro.

\section{DAFTAR PUSTAKA}

Adinegara, S. 2005. Volume Angkutan Sedimen Dipengaruhi Oleh Kecepatan Aliran Kajian : Laboratorium. Jurnal Media Komunikasi Teknik Sipil, 13 (2):94-105.

Agustini, N.T. Ta'alidin, Z. \& Purnama, D. 2016. Struktur Komunitas Mangrove Di Desa Kahyapu Pulau Enggano. Jurnal Enggano. 1(1):19-31.

Aritonang, A.E. Surbakti, H. \& Purwiyanto, A.I.S. 2016. Laju Pengendapan Sedimen Di Pulau Anakan Muara Sungai Banyuasin Provinsi Sumatera Selatan. Maspari Journal. 8(1):7-14.

Atmojo, W. 2011. Studi Penyebaran Sedimen Tersuspensi Di Muara Sungai Porong Kabupaten Pasuruan. Buletin Oseanografi Marina. 1:60-81.

Aysha, A., Abu Hena, M.K., Mishra, M., Nesarul, M.H., Padhi, B.K., Mishra, S.K., Islam, M.S., Idris, M.H. \& Masum, M.B., 2015. Sediment and carbon accumulation in sub-tropical salt marsh and mangrove habitats of north-eastern coast of Bay of Bengal, Indian Ocean. International Journal of Fisheries and Aquatic Studies, 2:184-189.

Hayati, N.F., Muhiddin, A.H. \& Amran, M.A. 2017. Profil Distribusi Dan Kondisi Mangrove Berdasarkan Pasang Surut Air Laut Di Pulau Bangkobangkoang Kecamatan Liukang Tupabbiring Kabupaten Pangkep. Spermonde. 3(1):47-52.

Hoque, M/M. Hena, A. Ahmed, O.H. Idris, M.H. Hoque, A.T.M. Rafiqul, M.M \& Billah, M.M. 2015. Can Mangroves Help Combat Sea Level Rise Through Sediment Accretion And Accumulation?. Malaysian Journal Of Science. 34(1):78-86.

Keputusan Menteri Negara Lingkungan Hidup. 2004. Peraturan Menteri Negara Lingkungan Hidup Nomor 201 Tahun 2004 tentang Kriteria Baku dan Pedoman Penentuan Kerusakan Mangrove, Jakarta.

Paputungan, M.S. Koropitan, A.F. Prartono, T. \& Lubis, A.A. 2017. Profil Akumulasi Sedimen Di Area Restorasi Mangrove, Teluk Lembar Pulau Lombok. Jurnal IImu Dan Teknologi Kelautan Tropis. 9 (1):301-313.

Petra, J.L. Sastrawibawa, S. \& Riyantini, I. 2012. Pengaruh Kerapatan Mangrove Terhadap Laju Sedimen Transpor Di Pantai Karangsong Kabupaten Indramayu. Jurnal Perikanan Dan Kelautan. 3(3):329-337.

Prawira, M.P. \& Pamungkas, A. 2014. Mitigasi Kawasan Rawan Banjir Rob Di Kawasan Pantai Utara Surabaya. Jurnal Teknik Pomits. 3(2):2301-9271

Satriadi, Alfi. 2012. Analisis Sebaran Sedimen Tersuspensi Di Perairan Paciran Lamongan Jawa Timur. Buletin Oseanografi Marina. 1:13-30.

Schwarzer, K. Thanh, N.C. \& Ricklefs, K. 2016. Sediment re-deposition in the mangrove environment of Can Gio, Saigon River estuary (Vietnam). Journal of Coastal Research, Special Issue. 75:138-142.

Setiawan, H. 2013. Status Ekologi Hutan Mangrove Pada Berbagai Tingkat Ketebalan. Jurnal Penelitian Kehutanan Wallacea. 2(2):104-120

Syahrial. 2018. Keadaan Hutan Mangrove Di Utara Indonesia Berdasarkan Indikator Kualitas Lingkungan Dan Indikator Ekologi Komunitas. Maspari Journal. 10(1):89-96.

Wantasen, A.S. 2013. Kondisi Kualitas Perairan dan Substrat Dasar Sebagai Faktor Pendukung Aktivitas Pertumbuhan Mangrove di Pantai Pesisir Desa Basaan I, Kabupaten Minahasa Tenggara. Jurnal IImiah Platax, 1(4):204-209.

Widjojo, S. 2010. Transportasi Sedimen Oleh Kombinasi Aliran Permanen Beraturan dan Gelombang Seragam. Jurnal Media Teknik Sipil. 10(2):75-80 